\title{
PRESENCIA Y DISPOSICIÓN DE LAS DISPUTATIONES METAPHYSICAE DE FRANCISCO SUÁREZ EN EL PROYECTO ONTOLÓGICO-EXISTENCIARIO DE MARTIN HEIDEGGER
}

\author{
PRESENCE AND DISPOSITION OF \\ FRANCISCO SUÁREZ'S DISPUTATIONES \\ METAPHYSICAE IN THE ONTOLOGICAL- \\ EXISTENTIAL PROJECT OF MARTIN HEIDEGGER
}

Ángel Poncela González*

\begin{abstract}
RESUMEN - Nuestro propósito se cifra en esta ocasión, en mostrar los motivos filosóficos que condujeron al Martin Heidegger a introducir la metafísica suareciana en la configuración de su ontología existenciaria. Tomaremos como hilo conductor la historia del ser y más en concreto, la de su olvido en favor del ente y que Heidegger desarrolló en diferentes escritos como un momento negativo, fundamental y previo a la exposición de su concepción de la Metafísica. En este relato dejaremos anotado, la función capital que para el proyecto heideggeriano de reinterpetación de la Metafísica desempeñó, la idea de la metafísica griega y en particular de la aristotélica alcanzada por el pensador alemán. Abordaremos este problema con cierta extensión pues sostenemos que el concepto de la metafísica suareciana manejado por Heidegger está determinado por su comprensión de la Metafísica de Aristóteles. Y que se resume en su conocida interpretación ontoteológica. En último término, el peso de la reflexión heideggeriana sobre la metafísica de Suárez, recae sobre el concepto de existencia
\end{abstract}

* Universidad de Salamanca. E-mail: aponcela@usal.es. La investigación necesaria para llevar a cabo este trabajo ha sido posible gracias a la financiación del Ministerio de Ciencia e Innovación y la Junta de Castilla y León a los proyectos de investigación siguientes: "Lexicografía y Ciencia: Otras fuentes para el estudio histórico del léxico especializado y análisis de las voces que contienen" (FFI2011-23200) y "La Filosofía de las pasiones en la Escuela de Salamanca" (SA378A11-1).

\begin{tabular}{|l|l|l|l|l|l|}
\hline Veritas & Porto Alegre & v. 56 & n. 2 & maio/ago. 2011 & p. 178-205 \\
\hline
\end{tabular}


y su modo de aprehensión que es comprendido como un antecedente moderno e imperfecto del Dasein como vía de acceso al Ser.

PALABRAS CLAVE - Aristóteles. Suárez. Heidegger. Metafísica. Ontología. Escolástica.

ABSTRACT - Our purpose is to show the philosophical reasons that led Martin Heidegger to introduce Suárez's metaphysics in the formation of his existential ontology. We will take as a guiding principle the history of "Being" and more specifically of its being forgotten in favor of "being", which Heidegger developed in several writings of him as a negative moment, but at the same time fundamental and previous to the presentation of his conception of metaphysics. In this account we will point out to the crucial role that was played, in the Heideggerian project of reinterpreting metaphysics, by the idea of Greek metaphysics and in particular of Aristotelian metaphysics. We shall address this issue at some length because we hold that the concept of Suárez's metaphysics in the view of Heidegger is very much determined by his understanding of Aristotle's metaphysics. This should be summarized in his well-known onto-theological interpretation. Ultimately, the weight of Heidegger's reflections on the metaphysics of Suárez rests on the concept of existence and its mode of apprehension, which is regarded as a modern and imperfect antecedent of the Dasein as the gateway to Being.

KEYWORDS: Aristotle. Suarez. Heidegger. Metaphysics. Ontology. Scholastics.

\section{Justificación y apunte histórico}

Esposito, en la introducción a la versión italiana de la conocida obra de Courtine, Suarez et le système de la métaphysique, señaló, las dos fuerzas determinantes presentes en la dirección que han tomado los estudios suarecianos sobre la Metafísica a lo largo del siglo XX, prolongándose hasta nuestros días: "se debe sobretodo a dos autores de nuestro siglo, cuales son Martin Heidegger y Étienne Gilson (...) el que Suárez haya sido considerado como un momento esencial, por no decir epocal, en el

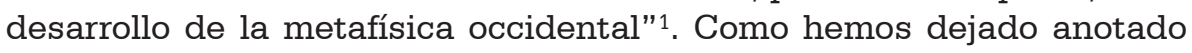
en otro lugar, en su vertiente positiva, el movimiento determinante en la rehabilitación de los estudios suarecianos durante la segunda mitad

1 Courtine, Jean-François. Il sistema Della metafisica. Tradizione aristotelica e svolta di Suárez. A cura di Constantino Esposito; Prefazione di Giovanni Reale. Vita e Pensiero, Milano, 1999; p. XIV. Resulta obligado hacer mención a otro escrito del autor que nos precede en la intención y con el que coincide nuestra línea discursiva aún persiguiendo unos intereses diversos a los nuestros y que hemos desarrollado de modo autónomo: Esposito, C. "Heidegger, Suárez e la storia dell'ontologia". Quaestio, 1 (2001), 407-430. 
del siglo pasado, procede de las menciones y análisis vertidos por Heidegger sobre el filósofo español. No aconteció así con la lectura crítica que en clave esencialista llevó a término Gilson de las Disputationes Metaphysicae y que aportó los argumentos negativos con los cuáles los antiguos herederos de la escuela realista atacaron a Suárez y a sus discípulos, amparados en la autoridad única del historiador parisino ${ }^{2}$.

Nuestro propósito se cifra en esta ocasión, en mostrar los motivos filosóficos que condujeron al Martin Heidegger a introducir la metafísica suareciana en la configuración de su ontología existenciaria. Tomaremos como hilo conductor la historia del ser y más en concreto, la de su olvido en favor del ente y que Heidegger desarrolló en diferentes escritos como un momento negativo, fundamental y previo a la exposición de su concepción de la Metafísica. En este relato dejaremos anotado, la función capital que para el proyecto heideggeriano de reinterpretación de la Metafísica desempeñó, la idea de la metafísica griega y en particular de la aristotélica alcanzada por el pensador alemán. Abordaremos este problema con cierta extensión pues sostenemos que el concepto de la metafísica suareciana manejado por Heidegger está determinado por su comprensión de la Metafísica de Aristóteles. Y ésta, que se resume en su conocida interpretación onto-teológica de la Metafísica, se halla influenciada a su vez por el debate historiográfico sostenido en Alemania a principios del siglo $\mathrm{XX}^{3}$.

2 Poncela González, Ángel. Francisco Suárez, lector de Metafísica $\Gamma$ y $\Delta$. Posibilidad y límite de la aplicación de la tesis onto-teológica a las Disputaciones Metafísicas. Editorial Celarayn. León, 2010.

3 Heidegger, estuvo al tanto del debate finisecular europeo entorno a la naturaleza de la Metafísica en los que participaron entre otros historiadores Natorp y Zeller. Quizá el ámbiente y las posiciones fundamentales de estos autores en la polémica, pudieron determinar los dos niveles que Heidegger distingue en los libros metafísicos: el estudio del "el ente que escrute de la forma mas adecuada la idea del ser", esto es, el ente supremo, y aquél otro nivel que intenta comprender "el ser del ente en general": La primera vía conduce en su opinión a una "explicación óntica del ente" y la segunda a la "interpretación ontológica del ser" que el siguió. La primera además, viene a coincidir con aquella que Aristóteles denomina investigación sobre la causa primera, y que Heidegger lee como Teología, para decantarse finalmente en favor de la segunda, la Ontología, a la que define como una indagación mas hermenéutica que científica, la cual tiene por objetivo la determinación del "sentido del ser en general". Especialmente significativo resulta su modo de privilegiar la ontología en prejuicio de la teología. En esta dirección, Heidegger se acerca a la valoración que de tales disciplinas dada por Natorp, el cuál comprendió la Ontología como la ciencia de lo trascendental, y en cambio, la Teología, como una adenda espuria que no pertenece a la metafísica aristotélica. Cfr. Natorp, P. "Thema und Disposition der aristotlischen Metaphysik", Philosophische Monatshefte 24 (1887), p. 49-50 y 52-3. E. Zeller. "Bericht on Natorp's Thema und Disposition der arist. Metaphysik", Arichiv fur Geschichte der Philosophic 2 (1889), p. 264-271. 
En efecto, los estudios suarecianos de las últimas tres décadas han experimentado un creciente interés por recuperar la metafísica de Suárez en la dirección impresa por la historiografía aristotélica contemporánea y mediada por la lectura heideggeriana de las Disputaciones Metafísicas. Una de las investigaciones en esta línea, se agrupa entorno al intento de reconstrucción de la presencia de Suárez en el pensamiento de Heidegger, bien sea aproximándose al estudio de su interpretación ontológica de la Metafísica, bien repensando los problemas que legó Suárez a la metafísica moderna siguiendo su diagnóstico.

Bien, vamos a desarrollar ambas líneas de investigación de manera conjunta con el propósito de mostrar los motivos filosóficos que explican la presencia de la metafísica suareciana en los escritos de Heidegger. Vamos a aprehender el concepto, el punto de inserción y la función que las Disputaciones Metafísicas, y de modo particular la disputación XXXI, desempeña en la edificación de la Ontología heideggeriana. Para cumplir este propósito, vamos a acudir a los lugares del corpus heideggeriano en los que aparece mencionado el filósofo español y que se reducen a los cuatro siguientes: Die Grundprobleme der Phänomenologie (1927), Sein und Zeit (1927), Die Grundbegriffe der Metaphysik. Welt - Endlichkeit Einsamkeit (1929) y el tomo segundo de la compilación editorial titulada Nietzsche, y que reune escritos posteriores a la década de los años treinta sobre el pensador de Röcken 4 .

Sobradamente conocido es el gusto mostrado por Heidegger por el pensamiento medieval y que le valió diversas críticas como el epíteto que

4 Die Grundprobleme der Phänomenologie. Trad. castellana del curso de Marburgo pertenciente al semenstre de verano de 1927: Martin Heidegger, Los problemas fundamentales de la fenomenología. Trotta, Madrid, 2000. En adelante, nos referiremos a esta obra, en el cuerpo y al pie, como Problemas. Sein und Zeit. Trad. castellana: Martin Heidegger, El Ser y el Tiempo. F. C. E. España, S.L., 1998. Die Grundbegriffe der Metaphysik. Welt - Endlichkeit - Einsamkeit. Trad. castellana del curso de Friburgo perteneciente al semestre de verano 1929/1930: Martin Heidegger, Los Conceptos fundamentales de la metafísica. Mundo - Finitud - Soledad. Alianza Editorial, Madrid, 2007. En adelante, nos referiremos a esta obra, en el cuerpo y al pie, como Conceptos. Nietzsche II. Ediciones Destino S. A., Barcelona, 2000. Nos referiremos exclusivamente a: La Metafísica como historia del ser, ed. cit., p. 325-373. Para Suárez: R. Patris Francisci Suarez. Metaphysicarum Disputationum, in quibus et universa naturalis theologia ordinate traditur \& quaestiones ad omnes duodecin Aristotelis libros pertinentes, acurate disputantes. Salmanticae, apud Ioannen \& Andream Renaut frates, 1597. Manejamos en el presente escrito la edición biligüe latin-español de las Disputationes de Francisco Suárez en 7 vol: Francisco Suárez. Disputaciones Metafísicas. Rábabe, S., Caballero, S. y Piugcerver, A. Eds. Editorial Gredos, Madrid, 1960-1966. En adelante, nos referiremos a esta obra al pie, como DM. Para Aristóteles, manejamos la edición trilingüe griego-latin-español: Metafísica de Aristóteles. Edición Trilingüe por García Yebra, V. Editorial Gredos, Madrid, 1998. En adelante, nos referiremos a esta obra al pie, como Meta. 
le adjudicó Ortega y Gasset: "Heidegger es ya quo ontólogo escolástico" 5. Pero nos interesamos aquí por el origen de la predilección mostrada por Suárez. Xavier Zubiri, díscipulo de los mencionados filósofos, en el prefacio a la traducción castellana del comentario al De anima de Suárez, recuerda que Heidegger se refería en los cursos de Friburgo a Suárez como: "Der ist der Mann", queriendo manifestar con ello, tanto la admiración profesada al granadino, como el carácter determinante de su pensamiento para el devenir de la Metafísica occidental ${ }^{6}$. En el mismo lugar, Zubiri, señala que Cohen y Natorp baluartes de la escuela neokantiana de Marburgo apuntaban a sus alumnos, la necesidad de acercarse a las obras filosóficas de Francisco Suárez. Conocida es la influencia que ejerció aquélla escuela sobre el joven Heidegger. En el siguiente pasaje el propio Heidegger indica cuál fue una de las vías de acceso a la metafísica suareciana: "El último año de mi época del Bachillerato había tropezado con el escrito del por aquél entonces catedrático de Dogmática de la Universidad de Friburgo, Carl Braig: Del ser. Compendio de ontología, que había aparecido en 1896, cuando su autor era profesor extraordinario de Filosofía en la Facultad friburguesa de Teología. Las secciones principales del escrito llevaban siempre al final largos textos de Aristóteles, de Tomás de Aquino y de Suárez, a más de la etimología de los términos correspondientes a los conceptos capitales de la ontología"7. No hace falta incidir más en la cuestión del origen del ascendente suareciano pues el filósofo nunca ocultó sus huellas intelectuales. Como dijimos, no nos hacemos cuestión

5 Molinuevo, J. L. y Hernández, D. "Papeles de Trabajo de José Ortega y Gasset". Revista de Estudios Ortegianos, números 2 y 3. Madrid, 2001; II, p. 11. Heidegger, era plenamente consciente de esta opinión generalizada, cómo evidencia la siguiente pasaje: "Se dice que mi trabajo filosófico es fenomenología católica. Probablemente porque soy de la convicción de que también pensadores como Tomás de Aquino o Duns Scoto han entendido algo de filosofía, quizá más que los modernos. El concepto de una fenomenología católica es sin embargo, aún más absurdo que el concepto de una matemática protestante". Problemas, p. 46.

6 Mas que un discípulo podría decirse de Zubiri, que estudió en la Universidad de Friburgo entre los años 1928-1930 con Husserl y Heidegger - siendo ya catedrático de Metafísica de la Universidad Central de Madrid -, un rival y un colega. Si, se declaró en cambio abiertamente, discípulo de Ortega. La cita en: Francisco Suárez, Commentaria una cum quaestionibus in libros Aristotelis "De Ánima", T. I, p. 3. Edición crítica por Salvador Castellote. Editorial Labor, Madrid, 1992 en 3 vols.

7 La obra citada por Heidegger de su profesor de Dogmática de la Universidad de Friburgo, Carl Braig es: Vom Sein. Abriß der Ontologie. Die Grundzüge der Philosophie IV, Freiburg im Bresg. 1896. Martin Heidegger. Tiempo y Ser. Madrid, Tecnos, 2000. Para un acercamiento a la figura y al pensamiento de Braig, Véase: Stegmüller, F. "Karl Braig (1853-1923)", in: Oberrheinisches Pastoralblatt, 54 (1953); p. 120-128. Leidlmair, K. Christliche Philosophie im katholischen Denken des 19. und 20. Jarhunderts. Emmerich Coreth, Ed. tomo I, Graz/Wien/Köln, 1987; p. 409-419. Existe una versión digital de la citada obra de Braig: http://www.freidok.uni-freiburg.de/volktexte/806. 
de los motivos históricos que condujeron a Heidegger a introducir a Suárez en el desarrollo de su pensamiento; nuestro interés se dirige hacia los filosóficos: a la función que pudo cumplir la lectura suareciana de la Metafísica en su proyecto ontológico del alemán.

Antes de adentrarnos en el análisis particular que hizo Heidegger de la tesis medieval en Problemas, y en particular de la solución aportada por Suárez a aquél problema, es necesario para su esclarecimiento, que de manera previa profundicemos en el concepto de la Metafísica manejado por Heidegger en su primer periodo filosófico. Seguimos para ello el hilo conductor enunciado, de la historia de la metafísica occidental como el relato trágico en el que el ser es olvidado a favor del ente.

\section{La traducción Metafísica del pensar originario: Fisis}

Partimos en nuestro análisis de los Conceptos. En la interpretación existencial de la Metafísica, en cuanto vinculada al destino general del hombre, que llevó a término Heidegger en las lecciones de 1929/1930, se aprecia el poderoso ascendente de Anaximandro y Heráclito. Veamos en qué sentido.

La Metafísica lejos de ser una mas dentro del cuadro de las disciplinas filosóficas, es una parte constitutiva, una cualidad del ente humano que afecta a la forma de comprender por un lado, su modo de ubicación en el mundo y por el otro, a la manera de dotar de sentido a través de las palabras (légein) a la propia existencia. El hombre cumple con su auténtico destino cuando piensa metafísicamente, esto es, cuando se afana en comprender la ley interna o naturaleza de lo que se impone y rige el ámbito de lo ente. La Metafísica, es en realidad, la expresión del anhelo propiamente humano por comprender la Ley o Verdad que se oculta en la naturaleza, con el fin de que el hombre pueda actuar conforme a su ley (katà físin) en el mundo y cumplir así con su naturaleza o destino ${ }^{8}$. El intento del hombre por comprender su destino es la tarea que la Metafísica eleva a ciencia. La Metafísica es por lo tanto, la conceptualización de un anhelo originario: la pregunta por el sentido de la existencia humana. Esta inquisición por el sentido no es más que preguntarse por "la auténtica naturaleza de la cosas" siendo conscientes de que esta empresa no es fácil, puesto que el sentido, la naturaleza

8 La conocida defensa heideggeriana a favor del modo de un modo de vida consecuente, es decir, propiamente humano (la "existencia auténtica") hay que entenderla desde el dolor o el estado de ánimo angustiado que provoca la comprensión de la verdad radical y su aceptación. 
"suele estar oculta"9. La naturaleza guarda celosamente su ley (lógos), su concepto al hombre pero este sirviéndose de la propiedad originaria de la palabra conferida por aquélla, es capaz de desocultar el secreto de la naturaleza. El riesgo de la empresa metafísica exige determinación puesto que el descubrimiento de la verdad provocará dolor. En efecto, del imperar esencial de la naturaleza de la Ley (lógos, ápeiron) en cuanto causa originante, procede la existencia de lo ente y también su inevitable destino: la finitud (katà tò jreón) ${ }^{10}$. La Metafísica, es un atentando contra el estado de inocencia en el que se halla la naturaleza de manera infinita. La Metafísica intenta, fundándose en la propiedad humana de la palabra, robar, arrancar el Logos a la naturaleza ${ }^{11}$. Esta apuesta por la verdad es una injusticia (adikías) que tendrá un alto coste para la existencia humana: "la disposición del tiempo" (tou jrónou táxin) ${ }^{12}$.

En términos menos poéticos hay que señalar finalmente, que Heidegger en estas lecciones, incluye en la naturaleza concebida no solo como ley sino también como ámbito, "al ente divino" pero solo "en cierto modo"13. En efecto, si la naturaleza como ámbito significa "todo lo ente" o el mundo, se impone en consecuencia, que Dios en tanto que ente, caiga también dentro del campo de investigación de la Metafísica. La naturaleza como el imperar esencial, el ser que se muestra a través de la palabra humana y que trata de explicar la Metafísica, experimenta un giro en el propio devenir de la de la historia del pensamiento occidental enajenándose a si mismo. El hombre deja de pensar linguísticamente el ser, su sentido, para preocuparse únicamente por las cosas en general que el propio ámbito le muestra como útiles.

La primera escena de este drama heideggeriano en tres actos periodo clásico, medieval y moderno de la Filosofía - titulado el "olvido del ser", versa sobre el primer indicio de transformación del pensar vital en pensamiento muerto o técnico, característico de la filosofía occidental,

9 Heráclito. Fr. 123, Temistio, Or. 5, p. 69 D. In: Kirk, Raven y Schofield. Los filósofos presocráticos. Gredos, Madrid, 1999, p. 280.

10 Heidegger en estas lecciones define la naturaleza en un doble sentido. En términos esenciales como "el imperar como tal", esto es, la esencia de una cosa; igualmente, desde un punto de vista espacial, la naturaleza es el "ámbito", el mundo, donde se ubica la totalidad de los entes. Ambas ideas están relacionadas y forman la unidad indisociable la naturaleza (físis). Como veremos mas adelante, será Aristóteles quien formalice filosóficamente estas intuiciones presocráticas, ofreciendo la posibilidad de quebrar esta unidad. Conceptos, p. 58.

11 Aristóteles, encontró en la palabra la prueba de la condición social del hombre y el fundamento de la organización política - Política 1253a. Heidegger, toma la palabra, como el lugar en el que el lógos de la naturaleza se hace manifiesto.

12 Anaximandro. Simplicio. Fís. 24, 11; DK 12 A 9. In: Kirk, Raven y Schofield. op. cit. p. 162.

13 Conceptos, p. 52. 
y que se concreta en los diálogos platónicos, que adquiere categoría científica (episteme) en los trabajos de su discípulo, Aristóteles ${ }^{14}$.

El error metafísico en el que cayó por vez primera Platón se enmarca en el ámbito de su teoría de las Ideas. Según Heidegger, con el mito de la caverna, Platón intentó responder con él a la pregunta por el ser. No obstante, en el relato platónico no sólo no trata del ser, sino que confunde el ser con el ente. Como ya hemos visto al inicio del ensayo, no es posible según Heidegger pensar el ser y en particular su sentido, sin saber lo que se piensa es decir, sin mantener la diferencia ontológica entre el ser y el ente. Es precisamente esta diferencia originaria la que queda enajenada en el mito, al sustituirla por no esencial: la diferencia entre "lo ente que es verdaderamente ente" - las ideas - y "lo ente que no es verdaderamente ente" - las cosas ${ }^{-15}$. A partir de este momento, el hombre de manera progresiva irá dejando de pensar el ser y tomará su simulacro: la representación del ente. Y todo ello, movido por una inclinación no existencial sino técnica.

El primer paso hacia la consumación técnica de la Metafísica la llevó a término Aristóteles con su representación científica del saber originario (episteme). El anhelo del hombre por dotar de sentido su existencia individual y finita, queda coagulado en la "Filosofía primera". Aristóteles con esta fusionó las dos direcciones de la físis, la esencia y el ámbito, haciendo uso de la diferencia platónica que queda interpreta como saber acerca de la sustancia (ousía) y de lo ente en general. En la episteme física aristotélica, la pregunta primordial es acerca del primer principio o causa motora de la naturaleza, y que denominó "lo divino" (to zeíon).

En opinión de Heidegger, los problemas que traerá consigo la síntesis aristotélica serán dos: la unidad sintética de las dos direcciones de la físis y la introducción del ethos filosófico. Por el primero, como atestigua la historia del pensamiento occidental será posible destinar toda la energía del pensar al estudio de lo ente olvidándose del ser. El segundo, conducirá a la configuración escolástica y disciplinar con la consiguiente reducción del objeto de la sabiduría originaria, la físis - como lo ente que existe por si mismo y lo que brota e impera desde si mismo - a su representación lingüística: un ente manejable, enseñable y producido por el hombre. Con la Metafísica, muere la sabiduría dando inicio a la Filosofía y a su destino occidental.

14 No es muy aventurado suponer que el "olvido del ser", sea la versión metafísica de la célebre "historia de un error" de carácter moral que pudo encontrar Heidegger en la lectura del Zaratustra nietzscheano.

15 Platons Lehre von der Wahrheit (1931-1932), En: GA 9. Martin Heidegger, La doctrina de Platón acerca de la verdad, en: Hitos, Alianza Editorial, Madrid, 2000, p. 173-198. 
Heidegger, contrapone la Teología de Aristóteles, con la Teología religiosa cristiana, con el fin de subrayar la diferencias, en términos que vienen a privilegiar a Aristóteles: "lo théion y lo theiotaton (de Aristóteles) no tiene nada que ver con la religiosidad, sino que significan, el ser autentico (timiotaton on) un concepto ontológico neutro. La teología es la ciencia del ente auténtico, la ciencia del ser"16. Esta última expresión parece rescatar la teología aristotélica del plano de la explicación óntica hacia la ontológica, lo cuál vendría sino a negar, al menos a relativizar, el diagnóstico del parágrafo 44 de Sein und Zeit.

El acento entre la teología aristotélica y la teología religiosa por un lado, y de la Teología respecto a la Ontología por otro, toma un rumbo diverso, en la conocida conferencia Was ist die Metaphysik? (1929), en la que identifica al ser del ente, con el ser, que es posible entrever a través del estudio de la Nada que ofrece la Metafísica como correlato objetivo. La Metafísica, entonces, es considerada, como una propedéutica a la Ontología, siempre y cuando el estudio del no-ser, no venga a contraponerse como se ha venido haciendo tradicionalmente por parte de la dogmática cristiana, al "ens increatum" o $\operatorname{Dios}^{17}$.

La determinación de la naturaleza de la Metafísica, continuaba siendo un asunto oscuro para Heidegger dos años después, en el curso universitario impartido en Friburgo dedicado al estudio del libro IX. Aquella cortesía intelectual que de manera intermitente hemos visto mantener con el Estagirita se quiebra de nuevo de manera radica ${ }^{18}$. Heidegger, volverá a subrayar a la Ontología como la ocupación genuina de la Metafísica y ello partiendo de un análisis preciso de uno de los temas de los que los estudios aristotélicos se han ocupado tradicionalmente: la unidad de la Metafísica.

16 Heidegger, M. El Ser y el Tiempo; Ed. cit.; p. 269.

17 Trad. Castellana: “¿Qué es Metafísica?” En: Martin Heidegger, Hitos. Alianza Editorial, Madrid, 2000, pp. 75-108.

18 He aquí una de las muestras del tono áspero mantenido a la hora de valorar la Metafísica: "¿Todavía no sabemos, de hecho, que es aquello que con tanta soltura llamamos metafísica? No. De esta palabra, hoy, tenemos solo la fascinación y la imagen del aura de profundidad y de redención que la circunda. Pero el hecho de llegar a saber que este tratado de Aristóteles es un tratado de Metafísica no sólo no dice nada, sino que además induce a error. Y esto no solo hoy, sino desde hace dos milenios. Qué es lo que mas tarde se comprendió con esta palabra y con su concepto, con "metafísica" de hecho, no ha estado en posesión ni de Aristóteles. Aristóteles, pues, no estuvo más próximo en la investigación de aquellos que desde las antigüedad creyeron trabajar sobre el nombre de metafísica". Heidegger, Martin. Aristóteles, Metaphysyk $\Theta$ 1-3. Von Wesen un Wirklichkeit der Kraft Metaphysik. Gesamtausgabe II. Abteilung: Vorlesungen 1923-1944. Vittorio Klostermann, Frankfurt am Main, 1981, p. 9. 
Siguiendo los pasos de Brentano en la interpretación de Aristóteles ${ }^{19}$, partió del análisis de los diversos sentidos que Aristóteles confiere al ente en el libro VI de la Metafísica ${ }^{20}$. Heidegger para cuadrar su Ontología, lleva a cabo una reducción del ente en cuanto tal al ser del ente, a partir de la lectura de la cuádruple división. En su opinión, éste es el sentido genuino que le otorga Aristóteles al objeto de la Metafísica, como puede apreciarse de manera clara en las siguientes palabras: "¿Qué es lo que poseemos y debemos decir del ente cuando lo tomamos sólo en cuanto ente? Nosotros decíamos que el ente es. Que él pone ente, el ente es el ser. Luego, cuando Aristóteles, habla de la multiplicidad de la distinción del ente en cuanto tal, habla de la multiplicidad del ser del ente" 21 . Los diversos modos de ser que viene a indicar la distinción introducida por Aristóteles, sólo indican cuatro maneras de significar el ente en cuanto ente. Pero como sabemos, la Ontología de Heidegger no tiene como destino el ente sino su ser, y por ello, aquellas cuatro formas de referirse al ente que tiene el ser, no mueren en la simple referencia lingüística, sino que son en realidad extensiones de significado del ser. Aquí reside precisamente, el fallo capital en el que cae la empresa de Aristóteles y que hereda la Metafísica occidental, el logicismo, que le lleva a tomar el medio por el fin en la investigación de la realidad 22 .

19 Fue una convicción de la investigación realizada por Brentano que en: "la discusión sobre los múltiples significados del ser, queda constituido el umbral de la Metafísica de Aristóteles". Brentano, Franz. Sui moltiplici significati dell'essere secondo Aristotele. Prefazione, introduzione, traduzione dei testi greci, progettazione e impostazione editoriale di Giovanni Reale. Trad. Del testo tudesco e indici di Stefano Tognoli. Vita e Pensiero, Milano, 1995. (Título Original: Von der mannigfachen Bedeutung des Seienden nach Aristoteles. Freiburg, 1862), p. 15. 93 Meta. VI, 2, 1026a 35-1026b 5; p. 308-9. 94 op. cit.; p.16.

20 Meta. VI, 2, 1026a 35-1026b 5; ed. cit, pp. 308-9. 93 Meta. VI, 2, 1026a 35-1026b 5; ed. cit, p. 308-9.

21 Conceptos, p.16.

22 "La lengua misma no puede ser el criterio - un punto de vista que solo hoy comenzamos lentamente a aceptar. Debemos liberar a la categoría de la lengua de la visión lógica como fue impuesta a partir de los tiempos de los Alejandrinos, indudablemente ya preparada por Platón y Aristóteles". Conceptos, p. 33. A la hora de resolver el interrogante acerca de la posible unidad de la Metafísica, Heidegger retoma el pasaje con el que Aristóteles abre el libro IX: "Hemos tratado acerca del Ente primero, al cual se refieren todas las demás categorías del Ente; es decir, acerca de la substancia (según el concepto de substancia se enuncian, en efecto los demás entes". Como ya dejamos indicado en una nota anterior, Heidegger, da cuerpo a su propuesta ontológica entorno al sentido del ser, interpretando sucesivamente al objeto, en sentido aristotélico como ente en cuanto tal, para después reducirlo al sentido fundante de su ciencia. En efecto, el texto de Aristóteles es traducido en estos términos: "Habíamos tratado del significado fundamental del ser que lleva y guía a todos los entes, significado al cual son reportados (o dichas) las restantes categorías, habíamos tratado de la ousía". Ibidem. 
En opinión de Heidegger, la reducción operada en Occidente del objeto de la Metafísica a substancia, y al desechar el camino de la pluralidad de los sentidos del ser ofrecidos por Aristóteles, la Metafísica quedó anegada bajo el peso del lenguaje olvidándose de buscar lo originario e implícito en la Metafísica y en el filosofar mismo: la búsqueda del ser a través de los sentidos abiertos por el ente desde el lenguaje ${ }^{23}$. En alguna ocasión incluso, la historia de la Metafísica occidental percibió uno de esos sentidos como camino, como sucedió con el estudio de la analogía como recurso para establecer la unidad de los dos planos de la realidad. Pero de nuevo, como vamos a ver a continuación, el pensamiento medieval en vez de tomar la sugerencia como punto de partida para emprender la búsqueda, y embarcada como estuvo en funciones impropias de la Metafísica, elevó el instrumento metodológico de la analogía a la categoría a problema y se quedó a morar en él ${ }^{24}$.

\section{La interpretación dogmático-cristiana de la Metafísica}

El segundo acto de la tragedia se consumó cuando los pensadores del medioevo trabaron conocimiento de la síntesis metafísica de Aristóteles mediada por la interpretación de los filósofos árabes. Esta opinión necesita de una precisión histórica. La Metafísica aparece en Occidente como una investigación sobre las propiedades y características (la esencia y sus predicados) de todas las cosas en general - ente y el ente en cuanto tal - y que al tiempo estudia los primeros principios, prestando especial atención a la causa suprema - lo ente en su conjunto y el ente principal. La Metafísica estructuralmente, es filosofía primera y teología.

En el contexto del pensamiento islámico esta estructura de la Metafísica fue puesta en cuestión. Avicena en su comentario a los metafísicos de Aristóteles se planteó expresamente la inclusión del estudio de Dios en la Metafísica. En su opinión, el conocimiento del ser

23 "Ya en el medioevo, en base a la proposición de Meta., IX, 1 (inicio) citada de sobra, se concluyó que el primer significado fundamental del ser, aunque por los cuatro modos en si y no por aquello de la categoría y de su multiplicidad, es la ousìa, que es traducida como "sustancia", Así, el ser posible, el ser real, el ser verdadero deben ser reconducidos en el sentido de la sustancia. En el siglo XIX (sobretodo con Brentano) se insiste mas sobre este punto, el ser posible y el ser real era reconocidos como categorías. Es alegada aquí una opinión corriente que la doctrina aristotélica del ser es una "doctrina de la sustancia". Esta interpretación está equivocada, en parte porque es insuficiente frente al pollajós; mas en concreto: no se recuerda que no se trataba mas que de la preparación de una pregunta". Conceptos, p. 35-6.

24 "Analogía del ser: esta determinación no es una respuesta dada a la pregunta sobre el ser y tampoco una efectiva elaboración de impostación de tal pregunta, sino que es el título para la más difíciles de las aporías (...) que había bloqueado el filosofar antiguo, y con eso, todo lo que vendría después hasta nuestros días". Conceptos, p. 36. 
divino excede las capacidades del hombre. El metafísico por lo tanto, ni puede probar racionalmente su existencia ni tampoco sus atributos y toda ciencia por definición ha de probar su objeto y no simplemente suponerlo. Por lo tanto, "Dios no puede ser el sujeto" de la Metafísica, sino que esta tiene "como sujeto principal el ente en cuanto ente"25. La Metafísica por lo tanto, adquiere aquélla estructura en Occidente, sólo cuando los libros son leídos a la luz de la dogmática cristiana medieval. Según Heidegger fue obra de Tomás de Aquino la transformación de la Metafísica aristotélica en teología racional que tiene por objeto el conocimiento de lo "trans-sensible" a través de una lectura causal del libro VI compatible con el paradigma creacionista en el que se inserta ${ }^{26}$. $\mathrm{El}$ objeto de la metafísica tomista, aprehendible racionalmente, no es el ser y tampoco el ente en general sino un ente determinado, el transsensible subdividido en el sumo ente (Dios) y el ente humano considerado únicamente desde el presupuesto de la inmortalidad.

A la transformación de la Metafísica aristotélica en una Teología racional le sucede la elevación de esta al rango de "scientia regulatrix" de las restantes disciplinas, cayendo bajo ella, la filosofía misma ${ }^{27}$. Heidegger lee el proemio al comentario de Tomás a la Metafísica en los términos siguientes: La Teología es la ciencia de lo máximamente intelectual, cognoscible, trans-sensible, según un triple modo: por el orden del conocer (ex ordine intelligendi), por comparación con el mero conocimiento sensible (ex comparatione intellectus ad sensum) y por el modo de conocer del intelecto (ex ipsa cognitione intelectus). Lo primero en el régimen del conocer es la causa primera que según el dogma cristiano es Dios creador (Filosofía primera). Lo máximamente inteligible son las determinaciones del ente en cuanto tal, las categorías (Metafísica como conocimiento categorial o Transphysica). El conocimiento de lo inmaterial y máximamente inteligible, el ámbito espiritual y en particular de Dios (scientia divina, Teología). La Metafísica en la interpretación tomista es "scientia regulatrix" en la medida en que reúne en una unidad de sentido, el estudio de los tres objetos y sus respectivas disciplinas.

\section{Las Disputationes Metaphysicae como tránsito a la interpretación moderna de la Metafísica}

De esta suerte, la filosofía queda reducida a ser un conocimiento entre otros perdiendo con ello sus características específicas: la autonomía

\footnotetext{
${ }_{25}$ Avicena, Al-Ilahiyyat (13 $3^{\mathrm{a}}$ parte del Kitab al-Sifà). En Avicena, Metafísica. Porro, P. y Lizzini, O. Bompiani, Milano, 2002. Tratado Primero, sección primera, p. 21 y 29.

26 Conceptos, p. 68.

27 Conceptos, p. 74.
} 
y la problematicidad propia del preguntar viviente. Esta herencia es recogida por toda la escolástica medieval y pasará a la modernidad bajo la interpretación del acervo metafísico realizado por Francisco Suárez. Los elementos estructurales del tercer acto de nuestro drama metafísico no afectan a nuestro estudio en la medida en que el presente escrito tiene por objeto llegar a la intepretación heideggeriana de la metafísica de Suárez.

El tercer periodo es homogéneo mas por sus defectos que por sus escasas virtudes, salvaguardando la crítica kantiana, que representa el primer intento de recuperación de la enajenada autonomía del pensar. La metafísica moderna es Ontología y se extiende desde las Disputationes Metaphysicae de Suárez (1597) hasta la transvaloración nietzscheana ${ }^{28}$. El pensamiento metafísico es un modo de preguntar peculiar en opinión de Heidegger pues no sólo se pregunta por todo lo ente sino que en esa misma inquisición, el hombre inquiriente queda incluido y por lo tanto puesto en cuestión. Este tipo de doble cuestionamiento propio de la investigación metafísica se pierde en la interpretación medieval como hemos visto. La metafísica del medievo estudia en efecto, el ente en su conjunto pero no se eleva a problema al sujeto de la pregunta. Los intereses son movilizados hacia el conocimiento del Sumo Ente y de la relación del alma humana inmortal con Él. En la metafísica moderna acontece un hecho paradójico, pues siendo considerado el yo, la conciencia, el fundamento absoluto de la metafísica de nuevo, el sujeto de la metafísica no se vuelve problemático ${ }^{29}$.

Como decíamos, la descripción de la modernidad tiene en si misma una importancia relativa, sabiendo que Heidegger, erigió al jesuíta granadino en el heraldo de la moderna Ontología: "En la acuñación escolástica pasa la ontología griega en lo esencial por el camino de las Disputationes metaphysicae de Suárez, a la "metafísica" y la filosofía trascendental de la Edad Moderna, y determina aún los fundamentos y las metas de la "lógica" de Hegel" 30 . Es posible completar el elogio de Heidegger hacia Suárez en Sein und Zeit con estas otras de las mencionadas lecciones de 1927 y de 1929 respectivamente. En las primeras, leemos: "Suárez fue el pensador que más poderosamente influyó en la filosofía moderna. Descartes depende directamente de él y usa su terminología casi por

28 Apoyamos nuestra decisión en el siguiente pasaje: "La teología y la dogmática cristiana se apoderaron de la Filosofía Antigua y la reinterpretaron de un modo totalmente determinado, de un modo cristiano (...) que se mantuvo a lo largo del Renacimiento (...) hasta el Idealismo alemán (...) y cuya falsedad sólo hoy comenzamos lentamente a comprender. El primero tal vez fuera Nietzsche". Conceptos, p. 68.

${ }^{29}$ Ibid., p. 82-83.

${ }^{30}$ Heidegger, Ser y Tiempo. Parágrafo 6, ed. cit, p. 32. 
doquier" ${ }^{31}$. Dos años más tarde, Heidegger continua manteniendo el mismo juicio sobre el filósofo español: "Suárez fue el primero en crear un desarrollo autónomo del problema metafísico, que fue de un influjo especial sobre todo para el comienzo de la filosofía moderna, para Descartes" ${ }^{32}$. En estas mismas lecciones aclara la naturaleza del gesto de autonomía que halla en la filosofía suareciana: la lectura aporética de la Metafísica y posterior ordenación que llevó a término en sus Disputationes: "Se planteó la tarea de interpretar de nuevo la metafísica aristotélica: el jesuita español Francisco Suárez" 33 .

El primer ascendente de Suárez sobre la filosofía moderna, procede de la lectura personal que llevó a cabo en sus Disputationes, sobre los libros metafísicos de Aristóteles. Este carácter autónomo, tanto de la lectura como del proyecto metafísico que Suárez lleva a cabo en su obra respecto de la Metafísica, es el primer motivo subrayado por Heidegger, y que Suárez puso de manifiesto en el prólogo general a que antepuso a la segunda disputación ${ }^{34}$. En este lugar, tras realizar una breve descripción de las dos partes en las que divide su obra - de la disputación I a la XXXVIII, y desde ésta a la LIV - justifica por razones instrumentales el primado, y al mismo tiempo, la cesura que existe entre la Metafísica y su proyecto con estas palabras de las que Heidegger también se hace eco: "Para proceder con mayor concisión y brevedad, y para poder tratar las cosas con método apropiado, nos abstendremos de prolijas explicaciones del texto aristotélico, y consideraremos las mismas cosas de que se ocupa esta sabiduría con el método doctrinal y expositivo que mejor se acomode a ellas" ${ }^{35}$.

Lo que se halla supuesto desde el comienzo de las Disputaciones Metafísicas, no es otra cosa que la pregunta por la Metafísica misma: el objeto, la naturaleza y el estatuto que confiere Suárez a la disciplina en el conjunto de los saberes, y de manera particular, el modo de relacionarse con la Teología. De ello es bien indicativo el título completo de la metafísica de Suárez, como Heidegger también apuntó: Metaphysicarum Disputationum, in quibus et universa naturalis theologia ordinate traditur \& quaestiones ad omnes duodecim Aristotelis libros pertinentes, acurate disputantes ${ }^{36}$.

Uno de los métodos que Suárez empleó para conducir su empresa fue la anexión al término de su obra, de un Index Locupletissimus

31 Problemas, p. 112.

32 Problemas, p. 80.

33 Conceptos, p. 79.

34 "Plan y método de doctrina que se ha de seguir en esta obra". DM II, ed. cit. Vol. I, p. 359-360.

35 Ídem.

${ }^{36}$ R. Patris Francisci Suarez. Metaphysicarum Disputationum, in quibus et universa naturalis theologia ordinate traditur \& quaestiones ad omnes duodecim Aristotelis libros pertinentes, acurate disputantes Salmanticae, apud Ioannen \& Andream Renaut frates, 1597. 
in Metaphysicam Aristotelis con el fin de proporcionar al lector un instrumento para poder establecer una lectura comparada entre ésta y su obra $^{37}$. En dicho Índice, Suárez reduce, siguiendo la costumbre heredada, los doce primeros libros de la Metafísica a un conjunto de cuestiones o problemas, pero sólo en contadas ocasiones, las acompaña con su opinión en aquellos casos en los que los problemas no encuentren tratamiento en el cuerpo de su obra. Lo que acomete Suárez allí, es una remisión, siempre aproximada, al artículo de una de sus disputas, en que la materia aristotélica es o expuesta parcialmente o bien utilizada para desarrollar un argumento ajeno a la mente de Aristóteles ${ }^{38}$.

No podemos dedicar mas espacio a la calificación de la lectura que de la Metafísica llevó a término Suárez en sus Disputationes, y tampoco es este el propósito del presente escrito. Ya dedicamos una monografía al estudio de tal problema y a ella remitimos al lector ${ }^{39}$. No obstante es necesario dar una serie de claves generales desde el punto de vista formal, máxime teniendo en cuenta que Heidegger tilda de teológica, como hemos dicho anteriormente, el propósito de la lectura de Suárez. La lectura de la Metafísica realizada por Suárez en esta obra, le condujo a elaborar un proyecto de restitución de la dignidad científica de una disciplina caída en descrédito por los excesos de las lecturas logicistas tradicionales y por el empirismo naciente.

En segundo lugar, hay que tener presente que la empresa que llevó a término Suárez no fue un gesto gratuito antes bien, fue una respuesta a la compleja situación ideológica de su tiempo y su modo de entender la misión a la que estaba llamado como miembro de la Compañía de Jesús. Suárez comprendió los "doce" libros del estagirita, adoptando maneras inusitadamente modernas, como reservorio de problemas, instrumentos e ideas susceptibles de ser aplicadas a la comprensión humana de la realidad creada por Dios. Las Disputaciones Metafísicas proponen en última instancia, una visión neutralizada de la realidad capaz de ser

37 "Índice detallado de la Metafísica de Aristóteles". Hay que precisar que en la primera edición de las DM (Salamanca, 1597) el Índice se encuentraba al comienzo del primero de los dos tomos que formaban la obra.

38 Distintas valoraciones sobre el Index suareciano de la Metafísica pueden encontrarse en: Martins, António Manuel. "Tópica Metafísica: De Fonseca a Suárez", En: Francisco Suárez (1548-1617). Tradiçao e Modernidade. Coord. Cardoso, A.; Martins A. M. y Ribeiro dos Santos, L. Ediçoes Colibri. Lisboa, 1999, p. 157-168. Coujou, Jean-Paul. Suárez et la Refondation de la Métaphysique comme Ontologie. Ètude et traduction d'Index détaillé de la Métaphysique d'Aristote de F. Suárez. Éditiones de l'Institut Supérieur de Philosophie. Éditions Peeters, Louvain la Neuve -Paris, 1999. Doyle, John P. A Commentary on Aristotle's Metaphysics (Index locupletissimus in Metaphysicam Aristotelis). Marquette University Press, Milwaukee, 2004, p. 9 y ss.

39 Ángel Poncela González. Francisco Suárez, lector de Metafísica $\Gamma$ y $\Delta$. Posibilidad y límite de la aplicación de la tesis onto-teológica a las Disputaciones Metafísicas. Editorial Celarayn. León, 2010. 
asumida por todos los hombres en tanto que seres dotados de racionalidad y con independencia de la ideología profesada. Aquí reside la originalidad de la lectura suareciana de la Metafísica y al tiempo su riesgo.

En opinión de Heidegger la lectura suareciana de la Metafísica aportó desde el punto de vista formal, una nueva sistematización de la ontología antigua y medieval, al dotar a la Metafísica de Aristóteles de la "estructura sistemática" de la que carecía. Para ello ordenó los problemas que presentaban los doce libros metafísicos en forma de catálogo, ofreciendo así la ordenación y la clave de lectura de los mismos. A partir de Suárez, en una clasificación que perdurará en el tiempo hasta Hegel, la Metafísica que Suárez leyó como Ontología, en el sentido del hipotético estado en el que se hallaba la realidad momentos antes de descender la revelación divina (Theología naturalis), en:

a) Ontología general (Metaphysica generalis)

b) Ontología natural o cosmología racional (Metaphysica specialis)

c) Ontología del espíritu (Psychologia rationalis)

d) Ontología de Dios (Theologia naturalis).

Una simple lectura de la disputación primera, evidencia que la división precedente de la Metafísica no pertenece a Suárez, sino a sus sucesores modernos comenzando por el inmediato sucesor de Suárez, también jesuíta y maestro en Praga, Rodrigo de Arriaga (1592-1622) tal cómo se refleja en la ordenación de materias de su Cursus Philosphicus (Amberes, 1632) que comienza a editar la Compañía de Jesús, tras las Disputationes Metaphysicae (1597) ${ }^{40}$. Fueron en puridad los Cursus, los que inspiran aquélla ordenación y que se reflejan en los trabajos de los

40 La lectura del Index suareciano de la Metafísica y de la primera disputación, nos ofrecen la siguiente división de los libros de Aristóteles: a) Introducción a la Metafísica: Libros I y II. B) Prólogo al lector. El libro III - libro de las aporías - comprendido como acicate al estudio de la disciplina. C) Cuestiones operativas (ontología del lenguaje). Es desarrollada en los libros IV y V. El VI recapitula lo obtenido en estos dos libros (la determinación del objeto de la disciplina). D) Tratado de la sustancia. Transita a lo largo de los libros VII a X: Estudio de la sustancia en general y de la sustancia segunda o universal (libro VII); la sustancia material o compuesta (VIII); principios dinámicos de la sustancia - el problema del cambio - (IX) y, finalmente, concluye Aristóteles con un análisis pormenorizado de la relación entre la unidad y la pluralidad -una cuestión ésta, ya presentada anteriormente en los libros IV y V, aunque de manera superficial, en opinión de Suárez. E) Recapitulación. Resumen general de la obra (XI) y del objeto principal de la disciplina, la sustancia, tal y como fue tratado en el libro VII, pero introduciendo ahora como colofón, doctrinas desarrolladas en el libro I de su Física, y algunas ideas sobre lo divino (XII). Para Suárez, la Metafísica tras pasar por un buen número de cuestiones introductorias y propedéuticas, podríamos decir, que es reducible a una usiología de carácter general. Con esta interpretación Suárez no se aleja, en principio, de la concepción cristiana de la Metafísica, y anticipa en buena medida, las lecturas aporéticas contemporáneas de los metafísicos: El objeto de la Metafísica es el ente real que es comprendido no como existencia sino como sustancia. Cfr: Suárez, Francisco. “Índice detallado de la Meafísica de Aristóteles", en: DM, ed. cit., Vol. 1, p. 20 a 178. 
ontológos modernos, J. Clauberg (1622-1665) y Ch. Wolf (1679-1764) entre otros ${ }^{41}$. Heidegger, por tanto, atribuyó de manera errónea, esa división de la Metafísica a Suárez, influenciado por la lectura moderna de Suárez de sus antiguos profesores de Teología ${ }^{42}$.

\section{Suárez y la tesis de la metafísica medieval}

Pero la influencia de Suárez sobre la metafísica moderna, aclara Heidegger, lejos de ser de carácter formal se extiende hacia "La acuñación de los problemas de contenido tal como a su vez despertarán luego en la filosofía moderna"43. Esta influencia suareciana sobre los contenidos o problemas filosóficos, Heidegger la analizó en las dos lecciones mencionadas, y en "La metafísica como historia del ser" de su Nietszche.

En Problemas, Heidegger presentó una primera reabsorción de la Metafísica en la Filosofía, seguida por una reducción de la última a Ontología: la filosofía es la ciencia del ser que lleva a cabo "una interpretación teórico-conceptual del ser, de su estructura y de sus posibilidades" 44 . El resto de saberes humanos son positivos pues parten de la presuposición del ente y lo elevan a objeto único y meta final de la investigación. La Filosofía, en cuanto Ontología, parte igualmente de un ente pero de uno muy determinado el "Dasein humano" que tiene como modo característico la posibilidad de comprender el ser. Este modo de ser característico del ente humano no es un supuesto sino el factum radical donde tiene lugar el encuentro con el ser. El ser es de suyo comprensible y el Dasein es el "ente comprendedor". Esta feliz coincidencia que Heidegger descubre a través de la aplicación del método fenomenológico u ontología existenciaria desarrollado dos años antes en Sein und Zeit, es la propiedad que eleva a la Filosofía a la categoría de ciencia comprendida como Ontología del ser ${ }^{45}$.

${ }^{41}$ Cfr. Wolf, Christian. Philosophia prima sive Ontología método científica pertractata qua omnis cognitionis humanae principia continentur. Editio tertia latina emendatior, Veronae 1786. Cfr. en particular el prólogo.

42 Vid. nota supra n. 7.

43 Conceptos, p. 79.

44 Problemas, p. 36.

45 En las lecciones impartidas durante el semestre estival de 1926, publicado bajo el título Los conceptos fundamentales de la filosofía antigua, Heidegger ya adelantó las líneas maestras de su lectura ontológica de la Metafísica. Distingue el ente como objeto de las ciencias positivas respecto del ser, que es considerado como el objeto propio de la filosofía. Para realizar esta separación de esferas a través de los objetos de cada ciencia, no dudó en interpretar la definición aristotélica de la Metafísica como "ciencia del ente en cuanto ente", como la empresa que conduce a investigar, el ser del ente, y no el ente. Die Grundbegriffe der antiken Philosophie (Sommersemester 1926). Vittorio Klostermann, Frankfurt am Main, 2004, p. 47. 
La Ontología tiene como objeto por definición el ser y no el ente, pero el ser no puede hallarse "in recto" sino mediante un método que propone el estudio del ser a través del fenómeno de los comportamientos humanos ordinarios con los otros entes, enmarcado en las coordenadas de la finitud y la temporalidad que les es propia también al Dasein. Heidegger es consciente del riesgo de ocultamiento que corre pareja a la búsqueda del ser a través del análisis de los fenómenos propios del ente humano, cuando el ser se revela al hombre dentro de su haber. Por este motivo fue necesario establecer, lo que denominó "el presupuesto fundamental" de la ontología, que no es otro que la "diferencia ontológica" (ontologische Differenz) esto es, la diferenciación entre el ser y los entes. Será en última instancia la temporalidad el fundamento de la diferencia pero para su establecimiento, de manera previa hay que ganar los conceptos y desbrozar el campo de problemas para el desarrollo de la Ontología. Heidegger, estuvo convencido de que en la historia de la filosofía occidental, no sólo en la Filosofía griega sino también en la Escolástica medieval, y con menos claridad en la filosofía moderna, el ser ya es concebido como problema. Heidegger es consciente de que su presupuesto fundamental de la diferencia ontológica, se aproxima quizá en exceso a la disputa escolástica entorno a la distinción, composición y articulación de todo ente (ens) en una naturaleza específica (essentia) y en un modo de ser determinado (existentia). Junto a la razón metódica, subrayar la originalidad de su propuesta filosófica es en segundo término, el otro motivo que explica el tratamiento por extenso que hizo en esta obra de la que denominó "la tesis, que se remonta a Aristóteles, de la ontología medieval" en la que pasa revista a las soluciones aportadas por Tomás de Aquino, Duns Scoto y Francisco Suárez ${ }^{46}$.

En este punto es necesario observar, que Heidegger partió en su estudio de la metafísica escolástica de una serie de presupuestos que actúan como instrumentos discursivos para encauzar la cuestión hacia su problema: el análisis fenomenológico de la existencia que llevó a cabo en la parte final del segundo capítulo de los Problemas y que consideraremos brevemente al término del presente ensayo, en lo que afecta a la lectura suareciana.

El primer presupuesto es por tanto obvio en la medida en que Heidegger si bien se mostró sensible hacia los desarrollos de la metafísica escolástica, considerada en si misma posee un interés subsidiario.

46 Heidegger es consciente de la proximidad que su investigación ontológica guarda con la filosofía escolástica y de la opinión que la comunidad científica alemana posee de su incipiente filosofía. En ese sentido leemos el siguiente diagnóstico: "Se dice que mi trabajo filosófico es fenomenología católica". Heidegger, Problemas, p. 46. 
Centrando aún mas el prejuicio sobre la cuestión de la diferencia ontológica, ésta, en su opinión, ni tan siquiera fue planteada por los escolásticos aunque si se hizo acuciante en cambio buscar una respuesta satisfactoria al problema de la distinción entre la naturaleza (essentia) y el modo de ser de un ente (existentia) y de cómo estos elementos se relacionan formando una unidad. Desde un punto de vista filosófico, la escolástica insertó el problema dentro del paradigma creacionista pero en cuanto teólogos, los escolásticos, tomaron la distinción como un medio racional capaz de comprender la especial naturaleza de Cristo. No obstante según Heidegger mas allá de esta dimensión teológica de la distinción, observó que el propio horizonte de la creación posibilitaba encuazar el problema desde un punto de vista exclusivamente filosófico. Suárez, es quien comprendió esta posibilidad en la disputación número XXVIII, estableciendo los límites del estudio en: "la distinción fundamental entre el ens infinitum, deus, y el ens finitum, creatura" 47 . Plantear el problema filosóficamente, es sinónimo de considerar "el problema de(l) modo mas agudo y correcto" posible, según Heidegger, y esto es lo que logró Suárez $^{48}$. Ahora bien, la aplicación de este método no sólo no asegura que el problema de la distinción pueda resolverse sino que incluso resulta "imposible progresar por este camino"49. En opinión de Heidegger, y como veremos más adelante, es la vía del análisis fenomenológico del comportamiento humano y no el modo moderno de preguntar, la que con mayores garantías nos aproxime a la comprensión del ser del ente humano.

Regresando a la lectura suareciana de la tesis de la metafísica medieval, la distinción escolástica se transforma en las Disputationes Metaphysicae en la pregunta sobre el tipo de relación que mantiene la existencia de un ente con su realidad. Habida cuenta de que desde el paradigma creacionista sólo es posible aplicar la pregunta al ámbito del ente finito, la distinción trata de clarificar de qué manera posee la existencia los entes finitos, a quienes por definición no les pertenece necesariamente como propiedad la existencia. La existencia del ens finitum no es un factum sino un mero posible que podrá ser actualizado o no. El problema es reinterpretado por Suárez en términos modernos, inquiriendo acerca del modo de actualización de la esencia de los entes finitos, y en particular, del individuo humano concebido en su posibilidad. Heidegger conectó en este punto, el tratamiento moderno suareciano directamente con la interpretación de la existencia ofrecida por Kant.

\footnotetext{
47 Problemas, p.112.

48 Ibid.

49 Problemas, p. 115.
} 
Heidegger, por lo tanto, no abordó la tesis de la metafísica medieval directamente sino partiendo del análisis de la solución moderna dada al problema de la relación/distinción de esencia y existencia. La existencia no es pensada por Kant en el predicado de la proposición, sino en su sujeto y por eso la existencia no es algo real que se predique de una cosa. No pertenece, por tanto la existencia a la esencia de una cosa sino que es un predicado del sujeto que lo piensa. Se sigue de esta interpretación que a la esencia de Dios no la pertenece la existencia. La relación de predicación siguiente "Dios es omnipotente", el ser copulativo, el "es" no dice nada sobre la existencia, esto es, no atribuye existencia a la esencia o concepto de Dios. Prueba de ello es que puede ser utilizado para establecer relaciones ente cosas imposibles como en la afirmación "El caballo es verde". Si afirmamos que "Dios es", en esta proposición existencial no se hace referencia a determinaciones reales de las cosas ni a sus relaciones, sino que lo que se pone en la cosa y es añadido a la representación o concepto, es una del objeto existente con su concepto o de una cosa efectiva consigo misma, en este caso Dios como sujeto. La existencia es concebida por Kant, no como algo real sino como "posición absoluta" del sujeto que pone su representación estableciendo así un modo de relación mental entre la cosa pensada (concepto) y el objeto efectivo sin que el concepto se vea por ello aumentado en su contenido por el ser del "es", por la existencia que se halla fuera del concepto ${ }^{50}$. En opinión de Heidegger, para Kant la existencia no es un atributo real pero sin embargo es algo, una posición absoluta del sujeto. Esta lectura, en opinión de Heidegger, se funda sobre una injustificada reducción de la existencia al fenómeno de la percepción. Pero el ser que es reducido al ser-percibido exige la perceptibilidad y esta, la propia existencia del ente percibido. Por lo tanto Heidegger subraya en el planteamiento kantiano un acercamiento el modo correcto de acceso al sentido del ser o existencia pero al tiempo un deficiente establecimiento del horizonte desde el cuál plantear el problema que es el del Dasein humano. Como decíamos más arriba, fue Suárez según Heidegger, el primer pensador moderno que se planteó el problema de la existencia desde el punto de vista de la conciencia.

Presentado de esta manera el problema, que vemos que es del establecimiento de la diferencia ontológica no por sí, sino como un paso previo al intento de comprensión del hecho de la existencia, ahora Heidegger se preguntó qué es lo que los escolásticos aportaron a la resolución de este problema.

50 Problemas, p. 66-70. 
Hemos visto hasta el momento como para el filósofo alemán, fue Suárez quien estableció la diferencia metodológica, y al tiempo los límites del campo de investigación de la Metafísica, en el ens infinitum/ ens finitum, partiendo de una lectura independiente o no teológica de los libros metafísicos de Aristóteles. No obstante, la cuestión de la diferencia como presupuesto, en su opinión, es extrapolable a toda la escolástica anterior a Suárez y se encuentra latente en las especulaciones de todos los medievales influidos todos ellos además por la lectura árabe de la Metafísica ${ }^{51}$.

La metafísica escolástica heredó la interpretación aristotélica y conceptual del ser, que supone no permitir que el ser se muestre en si mismo y por si mismo, sino concebirlo como o en cuanto ente. Igualmente, la escolástica heredó los problemas de la Metafísica. Aristóteles, comprendió el ser en sentido genérico, en cuanto ente, para estructurarlo después, en esencia y existencia; pero, como recordó Heidegger, el estagirita no explicó el modo en el que se relacionan ambos respectos para formar una unidad. La esencia, es lo que cada cosa es de acuerdo a su constitución antes de hacerse efectiva (to ti én eínai, quod quid erat esse, essentia realis). Sólo en la medida en que es pensable la esencia como algo posible o susceptible de hacerse efectivo, es como puede haber llegado a ser efectivo. Por el otro lado, la existencia (enérgeia, esse, existentia) es según la opinión escolástica dominante, "la actualidad o efectividad de toda forma y de toda naturaleza" ${ }^{52}$. El ente así

51 Heidegger, heredando un hábito consustancial a la tradición filosófica alemana contemporánea - baste recordar a Hegel en su Filosofía de la historia -, dedicó el mínimo espacio en sus obras a la análisis de la interpretación árabe de la Metafísica. En esta ocasión, hace remontar el problema medieval de la relación essentia/existentia a Avicena, sugiriendo que su lectura de la Metafísica aristotélica es errónea al estar mediada por las tradición neoplatónica del pseudo-Áristóteles; en concreto por el Liber de causis. No podemos entrar a valorar esta circunstancia histórico-filosófica en su justa dimensión y tampoco está en cuestión, el concepto de la filosofía aristotélica árabe (Fálsafa) manejado por Heidegger. Simplemente dejamos anotado que el problema de la distinción no se remonta a Avicena como supuso sino a al-Farabi, que fue quien inaguró en Oriente la lectura de la esencia en clave de posibilidad. Leemos al respecto: "Los seres son de dos clases. Con una de ellas se significan los seres cuya esencia no conlleva necesariamente la existencia; son los que se llaman seres posibles. Con la otra clase se significan los seres cuya esencia implica siempre la existencia; se llaman seres necesarios". Al-Farabi además, dejó planteado el problema justo en los términos en los que el problema sería abordado mas tarde por la escolástica occidental. En el mismo sentido, el siguiente pasaje: "En todas las cosas que existen hay esencia y también existencia. La esencia no es lo mismo que la existencia. Si la esencia de hombre fuese lo mismo que su existencia, entonces la concepción que tu tienes de la esencia de hombre sería misma que la que tienes de su existencia" (Al-Farabi 's philosophischen Abhandlungen aus Londoner. Dieterici, Brill, Leiden 1890; p. 57 y 66).

52 Problemas, p. 120. Cfr. Tomás de Aquino, Sum. Theol. I, q. 3, a. 4. 
interpretado es "lo real efectivo" propio del paradigma creacionista en el que se inserta la escolástica, a través de una interpretación del fenómeno de la causación ${ }^{53}$. El ente bajo la interpretación medieval como "lo real efectivo" significa que es algo efectuado (depende de una causa externa), un resultado u obra; que está situado en la realidad efectiva (subsiste) o puesto fuera de las causas que la afectuan (rei extra causas); que es en verdad lo que es (extra nihilum sistentia) y que a su vez es eficiente, es decir, que tiene capacidad para efectuar a su vez ${ }^{54}$.

El modo aristotélico de preguntar sobre el ente, a partir de la doble cuestión: ¿qué es (essentia) y que es (existentia) el ente?, asumido inopinadamente por la escolástica medieval, articula la tesis de la metafísica medieval enunciada por Heidegger de este modo: "a un ente le pertenece un qué (essentia, quididad) y un posible cómo (existentia, subsistentia)" puesto que no se encuentra en la naturaleza de todo ente que este exista de un modo necesario.

Esta tesis determina la concepción escolástica de la relación de los dos respectos estructurales del ente y que supone, en primer lugar, la existencia de un ente que es por si (ente a se) y en segundo lugar, de otros entes que son por otro (entis ab alio). Sólo en el ente por sí, la esencia y la existencia son metafísicamente inseparables, es decir, que la efectivdad pertenece a su esencia y que por lo tanto actua como causa primera, pura efectividad (actus purus) en el proceso de la causación. Es en el ente por otro o simplemente creado (ens creatum, ens finitum), donde acontece la composición y por lo tanto la distinción entre la esencia y su modo de ser, puesto que la existencia no pertenece a su esencia. La primera parte de la tesis, no resultó problemática para los escolásticos insertadas sus especulaciones en el paradigma creacionista monoteísta cristiano. No aconteció lo mismo con la segunda parte. No quedaba claro, en términos estrictamente racionales, el tipo de modo de ser (la entitas) del ente finito. Tampoco la clase de movimiento o modificación que experimenta el ente finito cuando su esencia es llevada a la actualidad. Ni la naturaleza de la causa que se añade a la esencia, en virtud de la cuál ésta existe o se hace real. Finalmente, se preguntaron si esta propiedad eficiente era una cosa real (res) y si así era en verdad, entonces cabía practicar algun tipo de distinción entre la essentia y la existentia. El problema de la distinción medieval por lo tanto, atañe exclusivamente al ente finito, y pregunta

53 No nos detenemos ahora a valorar esta lectura de Heidegger, que representa uno de los puntos de inflexión determinantes en el desarrollo de la metafísica occidental en cuanto "historia del ser" de la que habló en su Nietszche. La escolástica representa el paso de la comprensión originaria de la existencia como enérgeia a la existencia como actualitas o efectividad. Cfr. Nietzsche II, ed. cit, c. VIII, p. 337 y ss.

54 Nietzsche II, c. VII, p. 323. 
si en lo posible actualizado existe una distinción y si así acontece, cuál es su clase.

Todos los escolásticos, con independencia del partido filosófico que crearon o en el que militaron, admitieron la explicación anterior y reconocieron, la posibilidad de establecer una distinción estructural en el ente finito. En lo que se diferenciaron fue en el modo de calificar la distinción. Tres, como es sabido, fueron las respuestas escolásticas aportadas para intentar resolver el problema de la distinción. Para Tomás de Aquino, la distinción era una cosa real (distinctio realis); Duns Scoto, pensó que la distinción no era algo real en el ente sino un aspecto cualitativo, formal (distinctio formalis); por último, Francisco Suárez, supuso que la distinción era un producto forjado por la razón pero desprovista de realidad (distinctio rationis). Nos detenemos a continuación en la respuesta suareciana y posteriormente, en la valoración que Heidegger hizo de ella.

Fácil y muy común, debido seguramente al carácter abstracto de la cuestión, resulta pasar por alto el grave problema filosófico que entraña la disputa escolástica de la distinción. No es una cuestión de tipo nominal en la que estuviera en liza el epíteto más idóneo para engalanar la distinción, sino otro de tipo antropológico: el de la autonomía humana. Repárase en que si se admite que la efectividad es una cosa real que se añade a la esencia humana y que la situa en la existencia, se afirma al tiempo que entre el conjunto de propiedades que posee su naturaleza no se encuentra la capacidad de autoafirmarse, situarse, alzarse a través de su obrar en la realidad. Regresamos de nuevo a la situación originaria que nos presentaba el fragmento de Anaximando que citamos: la existencia no es una propiedad humana; y si osámos robarla a los dioses, pagaremos encontes, con el justo castigo de la finitud. Precisamente es a esta lectura existencialista de la distinción en general y mas precisamente, de la respuesta aportada por Suárez, a dónde conduce la investigación heideggeriana de la metafísica medieval y del filósofo español. En el último epígrafe, mencionaremos el segundo motivo que Heidegger halló consumado en el planteamiento suareciano de la metafísica: la consideración del ente no en cuanto tal sino como vía de acceso a la comprensión del sentido del ser o existencia. Dicho lo anterior, retomamos el análisis de la propuesta suareciana de la distinción racional o conceptual siguiendo la lectura heideggeriana de la misma.

Recordemos que la distinción racional de Suárez, supone que la existencia no es concebida por él como una cosa (res) o predicado, como antes vimos en Kant, sino que la diferencia entre la esencia y la existencia en el ente creado es puramente conceptual. Esta distinción viene a coincidir en el fondo con la distinción formal de Scoto pero 
Suárez aplicando el principio de economía racional, no cree necesario introducir un nuevo modo para explicar la diferencia. En la primera sección de la célebre disputación XXXI, Suárez lleva a término una aclaración del problema con la cuál intenta encerrar el problema en sus justos límites. Ésta, en opinión de Heidegger es uno de los aciertos de la síntesis escolástica suareciana. El problema de la distinción no versa fundamentalmente sobre como la esencia susceptible de actualización en cuanto posible, se distingue de su posterior existencia. La cuestión es mas sutil y apunta a como cabe distinguir, si es que es esto factible, en una cosa real (en el ente fáctico o "lo real efectivo"), la existencia y el contenido quiditativo de lo efectivo mismo. En opinión de Suárez, no puede distinguirse como un ente real, la existencia, pues constituye de manera "intrinsece et formaliter" con su esencia lo efectivo del ente real. La existencia no es por tanto una cosa (res) pues de mantener esta opinión, se seguiría que la esencia y existencia tendrían ambas un mismo ser y entonces nos encontraríamos con el problema de su modo de vinculación en una unidad existencial. Por lo tanto, según Suárez, es imposible considerar que la existencia sea una cosa, algo existente.

Si la distinción real conduce a una aporía irresoluble, entonces debemos preguntarnos de qué forma cabe concebir la relación entitativa. En opinión de Suárez, aplicando una distinción racional por la que la mente se representa no dos cosas distintas, sino sólo una misma cosa (el ser) pero a través de dos conceptos (esencia y existencia). Ahora bien, Suárez no pretende reducir los respectos del ente a meros conceptos sino que quiere subrayar el fundamento de la distinción ${ }^{55}$. Para ello retoma la distinción dialéctica común a la escolástica entre distinción lógica (distinctio rationis ratiocinantis) y distinción con fundamento en la realidad (distinctio rationis ratiocinata o cum fundamento in re). Mientras que el fundamento de la primera reside exclusivamente en la necesidad de comprensión del intelecto, en la segunda, acontece que el intelecto que aprehende, no sólo pone un concepto, sino que además se le contrapone de manera objetiva, en la representación, la propia realidad de la cosa concebida. Este último tipo es el que defiende Suárez y es además al que cabe reducir la distinción formal de Scoto.

Suárez, en la sección sexta de la disputación XXXI, reforzó su tesis, a saber: "que la esencia creada constituida actualmente fuera de las causas no se distingue realmente de la existencia de tal manera que sean dos realidades o entidades distintas", acudiendo al argumento de autoridad

55 Este punto es crucial para una justa comprensión no sólo de la disputación XXXI sino del conjunto de las Disputationes Metaphysicae. Para una ampliación de esta cuestión, cfr. nuestra obra citada nota 2 supra. 
de Aristóteles ${ }^{56}$. Según Suárez en ese pasaje lo que el estagirita quiso demostrar es que cualquier ente que se añada a una cosa real no le aporta nada nuevo. Por eso, es lo mismo afirmar "ente hombre" que "hombre" y esto demuestra que el ente en acto, es decir el existente, no añade nada nuevo al esencia actual o realidad. De aquí concluyó Suárez afirmando que por lo tanto añadir una nueva entidad a la realidad del ente creado es innecesario y las distinciones reales y modales, yerran.

Según Heidegger, Suárez extrajo de aquél pasaje la idea de que en toda cosa pensada, va incluido el ser; toda cosa, sea concebida en acto o en potencia, se la piensa siempre como siendo. Así acontece en el caso de la existencia. Suárez, en la sección segunda de la misma disputación a la hora de estudiar la esencia del ente creado recurrió al supuesto de pensar esa misma esencia antes de ser producida por Dios (Quid sit essentia creature, priusquam a Deo producatur) reforzando aún mas su tesis ${ }^{57}$. Antes de ser creada la esencia en la criatura "no es ninguna realidad, sino absolutamente nada", sentenció Suárez ${ }^{58}$. Y a la esencia concebida en ese estado, como pura posibilidad con respecto a su existir, nada pueda añadirle, por lo tanto la actualización divina. La esencia solo puede ser pensada como un algo sólo a partir del ente creado, de la esencia ya actualizada y es en este momento, y no en aquél, cuando puede ser captada su esencia o posibilidad como siendo. En la esencia actualizada, cabe concebirse lo que Suárez, denominó "potentia objectiva" - y que tomó del "esse diminutum" de Scoto ${ }^{59}$ como él mismo declaró - que "no consiste mas que en poder ofrecerse como objeto a alguna potencia, o mejor a la acción o causalidad de alguna potencia"60. Suárez, por un lado afirmó que cuándo la esencia es pensada en sí misma, entonces se sigue que la existencia no pertenece a su constitución quidditativa del ente creado; por el otro, que la existencia se haya ya de algún modo pero realmente presente en el interior de la constitución del ente creado, efectivo. Con esto Suárez, se alejó de la distinción realista de Tomás para el cuál fue necesario negar que la esencia no pertenecía a la existencia para que fuera posible mantener el dogma de la creación.

Llegados a este punto, afirmó Heidegger que a pesar de tomar un rumbo metodológico totalmente diverso al de la escuela tomista, pues

56 El pasaje que cita Suárez de la Metafísica es el siguiente: "pues lo mismo es "un hombre" que "hombre" y "hombre que es" que "hombre", y no significa cosa distinta "un hombre" que un "hombre que es". Metaph. IV 2, 1003b26-., ed. cit., p. 154. Cfr. Suárez, DM XXXI, s. VI, 1; ed. cit., Tomo V, p. 52.

${ }^{57} D M$ XXXI, s. II, 1, ed. cit., Tomo V, p. 21.

58 Ibid.

${ }^{59} D M X X X I$, s. III, 1, ed. cit., Tomo V, p. 31.

${ }^{60} D M$ XXXI, s. III, 4, ed. cit., Tomo V, p. 33. 
Suárez no fundamentó la distinción desde la necesidad de la creación sino a partir del ente creado, "nunca alcanza claridad al respecto"61. En opinión de Heidegger, Suárez pudo pensar a partir del ente creado, la existencia no como una cosa real, sino como cosa pensada que pertenece a su esencia en acto pero no a la esencia pensada en cuanto tal. La modernidad del planteamiento suareciano reside aquí y también su límite. Coincidirían los planteamientos de Suárez y Kant, según Heidegger, a la hora de considerar la existencia no como una cosa real. Difieren no obstante, en que para el primero, la existencia aun no siendo algo real, pertenece al ente creado, mientras que para Kant, la existencia se reduce en una relación epistemológica del sujeto con la cosa que la piensa.

Importa subrayar, antes de pasar a considerar brevemente y a modo de conclusión, la solución aportada por Heidegger al problema metafísico de la distinción, las ideas suarecianas que rescata y que asumió su pensamiento: que la existencia es pensable sólo a partir del ente y que sólo el ente humano posee la posibilidad de comprenderla. Hasta aquí llega la presencia de Suárez en el pensamiento heideggeriano y el motivo de sus referencias en sus lecciones universitarias.

\section{Conclusión: la existencia suareciana como momento de la "historia del Ser"}

La última referencia de Heidegger a Suárez, se encuentra en el tomo II de la obra titulada Nietzsche y que en realidad se trata de una complicación editorial del conjunto de las lecciones, seminarios, conferencias y escritos que realizara el filósofo alemán a partir de la década de los años treinta sobre la filosofía de Nietzsche.

Suárez, aparece mencionado en la interpretación histórica de la evolución de la Metafísica y que Heidegger denominó la "Historia del ser". En concreto, Suárez representa el momento clave en el paso de una concepción de la existencia como actualidad hacia otra en la que se convierte en la base cierta del sujeto pensante, propia de la modernidad.

Heidegger acudió nuevamente a la disputación metafísica número XXXI para recoger la definición suareciana de la "ex-sistencia", el ser que pone a un ente fuera de las causas, que lo hace existente y que Suárez identifica y equipara con la esencia actual, como acabamos de ver ${ }^{62}$. $\mathrm{Si}$ bien la existencia no es algo real, no obstante, como veíamos, por este

\footnotetext{
61 Problemas, p. 132.

62 Cfr. Nietzsche II, c. VIII, p. 341-342.
} 
camino no puede encontrarse ninguna solución, al estar determinada por el proceso de la causación. La existencia comprendida como actualidad, sólo cobra sentido en el ser eficiente que coloca a la esencia del ente fuera del proceso causal cuando es efectuado, superando así su ausencia de realidad.

Como vemos, aún encontrándonos con Suárez con el intento más decidido dentro de la escolástica medieval de comprensión de la existencia, el filósofo español no logra superar el umbral de la explicación óntica. Y ello es debido a que continua pensando en el paradigma creacionista regido por la dinámica causal. La existencia no adquiere sentido desde si misma en la metafísica suareciana sino siempre por referencia externa al summum ens eficiente. Suárez, no pudo avanzar en su concepción de la existencia al poseer como filósofo y teólogo cristiano la "convicción inquebrantable" de que todo ente había sido creado por $\operatorname{Dios}^{63}$. Suárez por lo tanto, aunque analiza detalladamente la existencia no para de ser una mas entre las interpretaciones escolásticas todas "muy escasas y rudimentarias" 64 . Pues si bien es correcto desde el punto de vista metodológico, atender a la existencia desde el ámbito de lo dado y observar aquí, que la existencia no es ningún tipo de relación de una cosa con otra sino "algo absoluto en si mismo" ("existentia rei absolute non est respectus, sed absolutum quid"), la existencia hace que algo sea actual sin ser aquélla nada actual. Pues si bien el ente actualizado es un existente por si mismo, la actualización la lleva a término Dios. Y por este camino, no obtenemos conocimiento de la existencia como tal sino del modo por el cuál un ente existe.

En definitiva, la existencia suareciana al ser interpretada a partir con el sujeto creador y no desde el sujeto que experimenta la existencia, la lectura escolástica y suareciana entró "en un callejón sin salida, del que nunca saldrá" ${ }^{65}$. Suárez, digamos que por su pertenencia al horizonte creacionista no pudo llegar a comprender a la existencia como lo que subsiste y es susceptible de producir efectos, sino que lo entendió lo subsistente como una cosa producida por otro y conclusa.

Careció Suárez, en última instancia del horizonte heideggeriano desde el cuál comprender la existencia: el comportamiento productivo del hombre (Dasein). Según Heidegger, sólo desde la experiencia de la existencia individual y reflexionando, fenomenológicamente, sobre nuestra capacidad productiva, podremos llegar a comprender la existencia

\footnotetext{
63 Problemas, p. 133.

64 "La existencia de una cosa absoluta no es una relación, sino que es algo absoluto"; cfr. DM XXXI, s. VI, 18, ed. cit., Tomo V, p. 66. Cfr. Problemas, p. 134.

65 Problemas, p. 138.
} 
como una determinación ontológica propia de ente humano y acercarnos entonces al Ser. Como para su caro Nietzsche, también la filosofía para Heidegger representó, en cierto modo, un juego fundado en la voluntad y en la originalidad:

Ich whone in meinen eigen Haus, Hab Niemandem nie nichts nachgemacht

Und-lachte noch jeden Meister aus,

Der nicht sich selber ausgelacht. ${ }^{66}$

${ }^{66}$ Cfr. Friedrich Nietzsche, Die Fröliche Wissenschaft ("la gaya o jovial ciencia"). E. W. Fritzsch, Leipzig, 1887. Trad.: "Yo vivo en mi propia casa, nunca he imitado a nadie - y me reí de todo maestro que no se haya reído de si mismo". 